\title{
STABILITY-INDICATING METHOD DEVELOPMENT AND VALIDATION FOR THE SIMULTANEOUS ESTIMATION OF ROSUVASTATIN CALCIUM AND CLOPIDOGREL BISULFATE IN PHARMACEUTICAL DOSAGE FORM BY REVERSE-PHASE HIGH-PERFORMANCE LIQUID CHROMATOGRAPHY
}

\author{
AWDHUT PIMPALE, RAJENDRA KAKDE* \\ Department of Pharmaceutical Sciences, Rashtrasant Tukadoji Maharaj Nagpur University, Nagpur, Maharashtra, India. \\ Email: drkakde@yahoo.com
}

Received: 23 April 2020, Revised and Accepted: 20 June 2020

\begin{abstract}
Objective: The present work was focused on the development and validation of reversed-phase high-performance liquid chromatography (RP-HPLC) method which is simple, rapid, precise, accurate, sensitive, economical, and stability-indicating for the quantification of rosuvastatin (RSV) calcium and clopidogrel bisulfate (CLO) in bulk and tablet formulation.
\end{abstract}

Methods: The separation was attained on RP Princeton (C18) column with dimensions (250 mm $\times 4.6 \mathrm{~mm}, 5 \mu$ ) employing buffer which is a mixture of water ( $\mathrm{pH} 3.0$, adjusted with orthophosphoric acid), and methanol in the ratio (20:80) v/v as mobile phase, at flow rate $1.0 \mathrm{ml} / \mathrm{min}$ and detection was carried out at wavelength $240 \mathrm{~nm}$. The retention time under the optimized condition of RSV calcium and CLO was found to be 2.844 min and $4.388 \mathrm{~min}$, respectively.

Results: The linearity of the method was demonstrated in the concentration range of $6-16 \mu \mathrm{g} / \mathrm{ml}$ and $45-120 \mu \mathrm{g} / \mathrm{ml}$ for RSV calcium and CLO with a correlation coefficient $\left(\mathrm{r}^{2}\right)$ of 0.9999 and 0.9996 , respectively. The percentage relative standard deviation was $<2 \%$ and percentage recovery was found to be $100.12-101.37 \%$ and $99.72-101.09 \%$ for RSV calcium and CLO, respectively. Assay of marketed tablet formulation was found to be 98.99\% and 99.92\%, respectively.

Conclusion: The developed RP-HPLC method was found to be simple, specific, sensitive, rapid, linear, accurate, precise, and economical and could be used for regular quality control of RSV calcium and CLO in bulk and tablet formulations.

Keywords: Rosuvastatin calcium, Clopidogrel bisulfate, Reversed-phase high-performance liquid chromatography, Validation, International conference on harmonization guidelines.

(C) 2020 The Authors. Published by Innovare Academic Sciences Pvt Ltd. This is an open access article under the CC BY license (http://creativecommons. org/licenses/by/4. 0/) DOI: http://dx.doi.org/10.22159/ajpcr.2020.v13i9.38013

\section{INTRODUCTION}

Rosuvastatin (RSV) calcium is chemically (3R,5R)-7-[4-(4Fluorophenyl)-2-[methyl(methylsulfonyl)amino]-6-propan-2ylpyrimidin-5-yl]-3,5-dihydroxyhept-6enoic acid (Fig. 1) [1]. It is an HMG-CoA reductase inhibitor used in the treatment of hypertension and abnormal lipid [2]. Clopidogrel bisulfate (CLO) is chemically Methyl 2-(2- Chlorophenyl) -2-(6, 7-dihydro thieno [3,2-C] Pyridine$5(4 \mathrm{H})$-yl) acetate sulfate (Fig. 2) [3]. It is an anti-platelet agent as an ADP receptor blocker mainly to treat patients with the acute coronary syndrome, myocardial infarction, peripheral vascular disease, and some stroke (ischemic type) patients [4]. An extensive literature survey revealed that several high-performance liquid chromatography (HPLC) should be methods were reported for the estimation of RSV calcium and CLO in bulk and tablet formulation [5-27]. The International Conference on Harmonization (ICH) guideline entitled "Stability testing of new drug substances and products" requires that stress testing be administered to elucidate the inherent stability characteristics of the active substance [28]. An ideal stability-indicating technique is one that resolves the drug, and its degradation products efficiently. Consequently, the implementation of an analytical methodology to work out RSV and CLO, in the presence of its degradation products is sort of a challenge for pharmaceutical analysts. Therefore, it was thought necessary to study the stability of RSV and CLO under acidic, alkaline, hydrolytic, oxidative, light, and thermal conditions. The reported methods have the drawbacks of long runtime and less economical with a high proportion of organic phase. Hence, an attempt was made to develop RP-HPLC method which is simple, rapid, accurate, precise, specific, economical, sensitive, and stability-indicating for the estimation of RSV calcium and CLO in bulk and tablet formulations.

\section{METHODS}

Chemicals and reagents

Pharmaceutical grade RSV calcium and CLO were procured as a gift sample from Cadila Pharmaceuticals Ltd., Ahmedabad (India), Rosmi $\mathrm{CV}$, a tablet formulation, obtained commercially.

Methanol, orthophosphoric acid, hydrochloric acid, sodium hydroxide, and hydrogen peroxide $30 \%$ of analytical grade were used throughout the work.

\section{Instrumentation}

Shimadzu HPLC system and PDA detector with Lab Solution software were used.

\section{Chromatographic conditions}

Chromatographic separation was achieved on a reversed-phase (RP) Princeton (C18) column with dimensions (250 $\mathrm{mm} \times 4.6 \mathrm{~mm}, 5 \mu)$ at ambient temperature using a mobile phase consisting of a mixture of buffer ( $\mathrm{pH}$ 3.0, adjusted with orthophosphoric acid), and methanol in the ratio of $(20: 80) \mathrm{v} / \mathrm{v}$ at a flow rate of $1.0 \mathrm{ml} / \mathrm{min}$. Detection was carried out at $240 \mathrm{~nm}$. The $\mathrm{pH}$ of the mobile phase was set at 3.0, and a column temperature of $30^{\circ} \mathrm{C}$. The injection volume was $10 \mu \mathrm{l}$. The optimized chromatographic conditions are shown in Table 1. 
<smiles>CC(C)c1nc(N(C)S(C)(=O)=O)nc(-c2ccc(F)cc2)c1/C=C/[C@@H](O)C[C@@H](O)CC(=O)[O-]</smiles>

Fig. 1: Chemical structure of rosuvastatin calcium

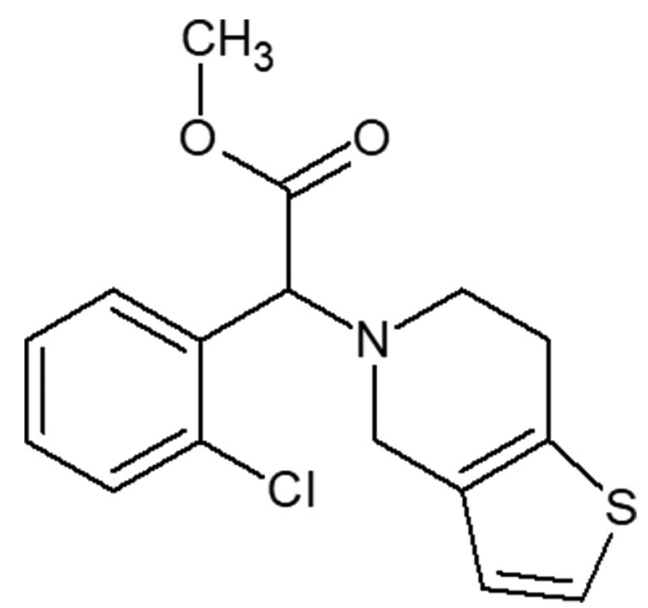

Fig. 2: Chemical structure of clopidogrel bisulfate

Table 1: Optimized chromatographic condition

\begin{tabular}{|c|c|}
\hline Parameters & Chromatographic condition \\
\hline Mobile phase & $\begin{array}{l}\text { Water (pH adjusted to } 3.0 \text { with } \\
\text { orthophosphoric acid):Methanol }(20: 80) \mathrm{v} / \mathrm{v}\end{array}$ \\
\hline Flow rate & $1.0 \mathrm{ml} / \mathrm{min}$ \\
\hline Column & Princeton C18 $(250 \mathrm{~mm} \times 4.6 \mathrm{~mm}, 5 \mu)$ \\
\hline Detector wavelength & $240 \mathrm{~nm}$ \\
\hline Column temperature & $30^{\circ} \mathrm{C}$ \\
\hline Injection volume & $10 \mu \mathrm{l}$ \\
\hline Runtime & $20 \mathrm{~min}$ \\
\hline Diluent & Methanol \\
\hline Retention time & $\begin{array}{l}\text { About } 2.844 \mathrm{~min} \text { for rosuvastatin calcium } \\
\text { peak and } 4.388 \text { min for clopidogrel bisulfate } \\
\text { peak }\end{array}$ \\
\hline
\end{tabular}

\section{Preparation of standard solution of RSV and CLO}

For RSV, an accurately weighed $1.0 \mathrm{mg}$ of RSV was transferred to a $10.0 \mathrm{ml}$ volumetric flask and dissolved in $5.0 \mathrm{ml}$ of methanol. The volume was completed to $10.0 \mathrm{ml}$ with methanol. One milliliter of the resulting solution was pipetted in $10.0 \mathrm{ml}$ volumetric flask and the volume was made up to $10.0 \mathrm{ml}$ with methanol to furnish a solution of concentration $10 \mu \mathrm{g} / \mathrm{ml}$ of RSV. For CLO, an accurately weighed $7.5 \mathrm{mg}$ of CLO was transferred to a $10.0 \mathrm{ml}$ volumetric flask and dissolved in $5.0 \mathrm{ml}$ of methanol. The volume was completed to $10.0 \mathrm{ml}$ with methanol. One milliliter of the resulting solution was pipetted in $10.0 \mathrm{ml}$ volumetric flask, and the volume was made up to $10.0 \mathrm{ml}$ with methanol to furnish a solution of concentration $75 \mu \mathrm{g} / \mathrm{ml}$ of CLO. For the working mixed standard solution, an accurately weighed $1.0 \mathrm{mg}$ of RSV and $7.5 \mathrm{mg}$ of CLO were transferred to a $10.0 \mathrm{ml}$ volumetric flask and dissolved in $5.0 \mathrm{ml}$ of methanol. The volume was completed to $10.0 \mathrm{ml}$ with methanol. One milliliter of the resulting solution was pipetted in $10.0 \mathrm{ml}$ volumetric flask and the volume was made up to $10.0 \mathrm{ml}$ with methanol to furnish a solution of concentration $10 \mu \mathrm{g} / \mathrm{ml}$ and $75 \mu \mathrm{g} / \mathrm{ml}$ of RSV and CLO, respectively.

\section{Preparation of sample solution of RSV and CLO}

Twenty tablets were weighed and finely powdered. An accurately weighed amount of powder equivalent to $1.0 \mathrm{mg}$ of RSV and $7.5 \mathrm{mg}$ of CLO was transferred into a $10.0 \mathrm{ml}$ volumetric flask. Then, $5.0 \mathrm{ml}$ of methanol was added in it. The flask contents were sonicated for $10 \mathrm{~min}$ to make the contents homogeneous. This solution was then diluted up to the mark with methanol. The resultant solution was filtered through Whatman Grade I filter paper. One milliliter of the filtrate was transferred to a $10 \mathrm{ml}$ volumetric flask and then the volume was made up to the mark with methanol to furnish a sample solution containing $10 \mu \mathrm{g} / \mathrm{ml}$ of RSV and $75 \mu \mathrm{g} / \mathrm{ml}$ of CLO. Six replicate of tablet powder equivalent to $1.0 \mathrm{mg}$ of RSV and $7.5 \mathrm{mg}$ of CLO was transferred into six $10.0 \mathrm{ml}$ volumetric flask, and homogeneous sample solutions were prepared similarly.

\section{Method Validation}

The developed method was validated following ICH guidelines (ICH Q2R1) for accuracy, precision, specificity, linearity, limit of detection (LOD), limit of quantification (LOQ), and robustness [29].

\section{Accuracy}

The accuracy of an analytical procedure expresses the closeness of agreement between the value, which is accepted either as a standard true value or an accepted reference value, and therefore, the value found. It was computed at three different levels, that is., 80,100 , and $120 \%$ of the label claim. Standard addition and recovery experiments were conducted to determine the accuracy of RSV and CLO for the quantification of drugs in the samples.

\section{Precision}

The system precision was evaluated by measuring the area of six qualified working standards for RSV and CLO and calculating the percentage of relative standard deviation (RSD). The assay method precision was evaluated by conducting six independent assays of test samples of RSV and CLO against qualified working standards and calculating the percentage of RSD.

\section{Linearity}

Linearity test solutions of RSV and CLO were prepared at concentration levels of $6-16 \mu \mathrm{g} / \mathrm{ml}$ and $45-120 \mu \mathrm{g} / \mathrm{ml}$, respectively. Linearity test solutions were prepared by diluting the stock solution to the required concentrations. Linearity was established by the least-squares linear regression analysis of the calibration data. Peak areas were plotted against the respective concentrations and linear regression analysis performed on the resulting curves. The linear curve of RSV calcium and CLO was shown in Figs. 3 and 4, respectively.

\section{Specificity}

The specificity of the developed method was established by comparing the chromatograph of the standard and sample. It was found that there was no interference due to excipients and impurities at the retention time of the drug.

\section{LOD and LOQ}

The LOD is the lowest analyte concentration that can be detected. LOQ is the lowest analyte concentration that can be quantified with acceptable accuracy and precision. The LOD and LOQ were calculated from the standard deviation of the response and the slope of the calibration plot. LOD and LOQ were established, under ICH definitions, by use of the equations $\mathrm{LOD}=3.3 \sigma / \mathrm{S}$ and $\mathrm{LOQ}=10 \sigma / \mathrm{S}$, where $\sigma$ is the standard deviation of the regression line and $S$ is the slope of the calibration plot 


\section{Robustness}

To evaluate the robustness of the developed method, the chromatographic conditions were deliberately altered and the resolution between RSV and CLO was evaluated. To study the effect

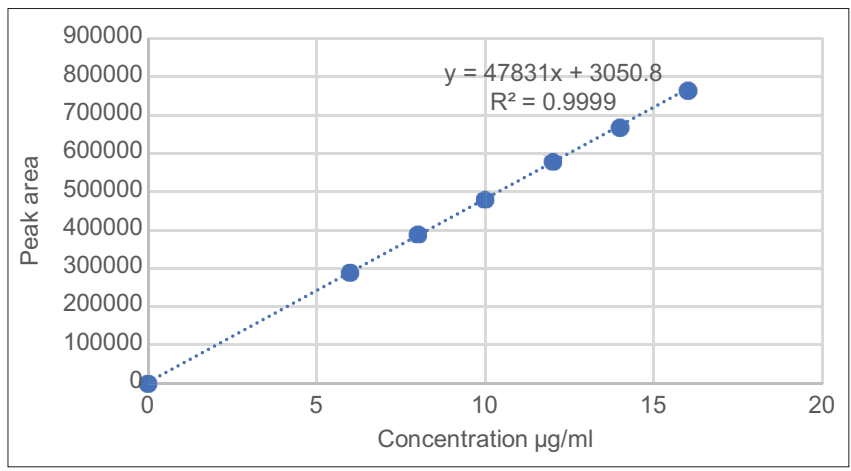

Fig. 3: Linear curve of rosuvastatin calcium

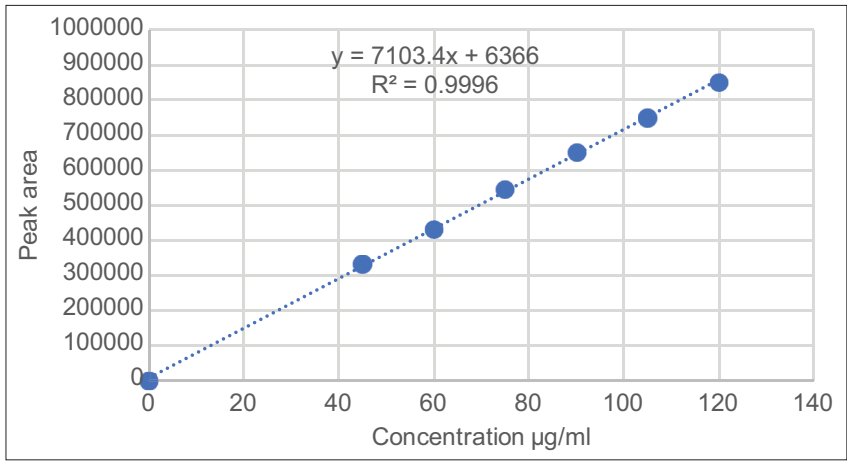

Fig. 4: Linear curve of clopidogrel bisulfate of wavelength on the estimation, the wavelength was altered by \pm $2 \mathrm{~nm}$, that is, 238 and $242 \mathrm{~nm}$ from the actual wavelength, $240 \mathrm{~nm}$. To study the effect of flow rate on estimation, the flow rate was altered by $\pm 0.1 \mathrm{ml} / \mathrm{min}$, that is, 0.9 and $1.1 \mathrm{ml} / \mathrm{min}$ from the actual flow rate, $1.0 \mathrm{ml} / \mathrm{min}$.

\section{Stability of the solution}

The stability of both the standard and sample solution was checked up to $24 \mathrm{~h}$ at room temperature.

\section{Stability-indicating assay}

The drug was subjected to acidic $(0.1 \mathrm{~N} \mathrm{HCl})$, alkaline $(0.1 \mathrm{~N} \mathrm{NaOH})$, oxidative $\left(0.3 \% \mathrm{H}_{2} \mathrm{O}_{2}\right)$, photo (light), thermal (sand bath at $50^{\circ} \mathrm{C}$ ), and hydrolytic (water) condition and the percentage degradation was calculated.

\section{RESULTS AND DISCUSSION}

\section{HPLC method development and optimization}

Initially, pure drugs solution was chromatographed using a mobile phase consisting of a mixture of buffer $(\mathrm{pH} 3.0$, adjusted with orthophosphoric acid), and methanol in the ratio of $(20: 80) \mathrm{v} / \mathrm{v}$ at a flow rate of $1.0 \mathrm{ml} / \mathrm{min}$ gives well-resolved peaks of drugs as well. Detection was carried out at $240 \mathrm{~nm}$. The retention time under the optimized condition of RSV calcium and CLO was found to be $2.844 \mathrm{~min}$ and $4.388 \mathrm{~min}$, respectively. The total run time of the chromatogram was about $20 \mathrm{~min}$. A typical chromatograph of a mixture of standard and sample of RSV calcium and CLO was shown in Figs. 5 and 6, respectively.

\section{Validation of the method}

System suitability

The suitability of the system was demonstrated by assessing various parameters. It was established by injecting six replicate injections of the standard solution. Theoretical plates were found to be 2816 and 3811, tailing factor of 1.60 and 1.54, and \%RSD of peak area was 0.9 and

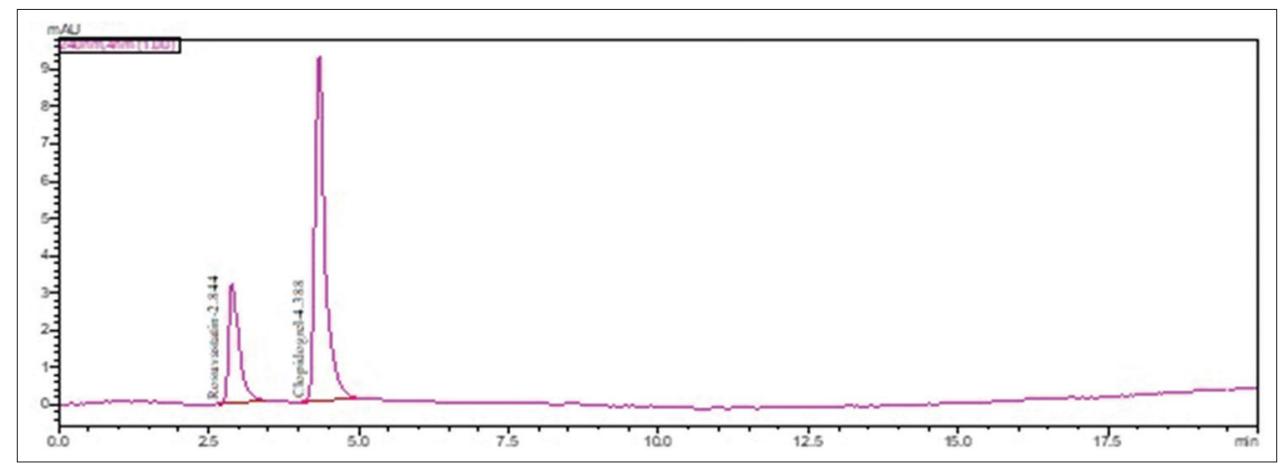

Fig. 5: Chromatogram of mixture of standard RSV and CLO. Rosuvastatin calcium (RSV) and clopidogrel bisulfate (CLO) with Rt of 2.844 $\mathrm{min}$ and $4.388 \mathrm{~min}$, respectively

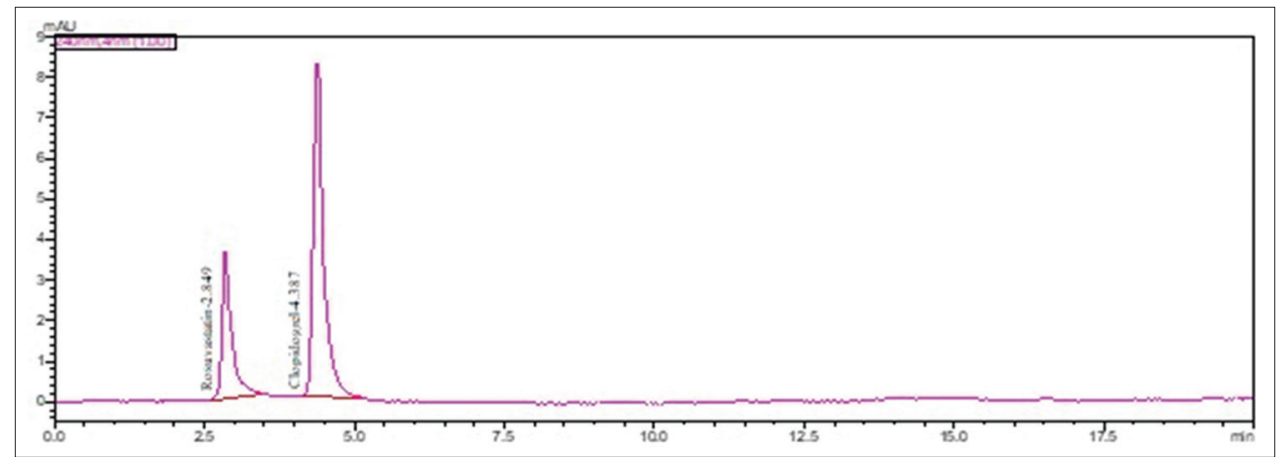

Fig. 6: Chromatogram of mixture of sample RSV and CLO. Rosuvastatin calcium (RSV) and clopidogrel bisulfate (CLO) with Rt of 2.849 min and $4.387 \mathrm{~min}$, respectively 
0.8 for RSV and CLO, respectively (Table 2). All the system suitability parameters were well within limits, indicating that the system was well suitable for performing the analysis.

\section{Linearity}

Linearity was established by the least-squares linear regression analysis of the calibration data. Calibration plots were linear over the concentration range of $6-16 \mu \mathrm{g} / \mathrm{ml}$ for RSV and $45-120$ $\mu \mathrm{g} / \mathrm{ml}$ for CLO. Peak areas were plotted against the respective concentrations and linear regression analysis performed on the resulting curves. The linear curve of RSV calcium and CLO was shown in Figs. 3 and 4, respectively. The linear regression equation obtained was $Y=47831 x+3050.8$ for RSV and $Y=7103.4 x+6366$ for CLO with correlation coefficient 0.9999 and 0.9996 , respectively. The results of linearity are shown in Table 3.

\section{Accuracy}

Accuracy was computed by recoveries studies. The mean percentage recoveries values for three levels were found to be between 100.12$101.37 \%$ and $99.72-101.09 \%$ for RSV and CLO, respectively. The percentage recoveries values within limits, indicating the method developed was accurate. The results of recovery are shown in Table 4.

\section{Precision}

The results of intraday precision and interday precision were 0.9 and 0.6 for RSV. The results of intraday precision and interday precision were 0.8 and 0.4 for CLO. The percentage RSD of system, method, and intermediate precision study was well within limits $(<2 \%)$, indicate that the method was precise.

\section{LOD and LOQ}

The LOD was found to be $0.65 \mu \mathrm{g} / \mathrm{ml}$ for RSV and $6.90 \mu \mathrm{g} / \mathrm{ml}$ for CLO. The LOQ was found to be $1.98 \mu \mathrm{g} / \mathrm{ml}$ for RSV and $20.91 \mu \mathrm{g} / \mathrm{ml}$ for CLO. The values of LOD and LOQ indicate that the method was greatly sensitive (Table 5).

\section{Robustness}

Robustness of the method was designed by changing the optimized condition adequately. To evaluate the robustness of the developed method, the chromatographic conditions were deliberately altered and the resolution between RSV and CLO was evaluated. On the assessment

Table 2: System suitability results

\begin{tabular}{lll}
\hline Parameter & RSV & CLO \\
\hline Theoretical plate & 2816 & 3811 \\
Retention time (Rt) & 2.844 & 4.388 \\
Tailing factor & 1.60 & 1.54 \\
$\%$ RSD & 0.9 & 0.8
\end{tabular}

Rt: Retention time, \%RSD: Percentage relative standard deviation. RSV: Rosuvastatin, CLO: Clopidogrel bisulfate

Table 3: Linearity results

\begin{tabular}{lll}
\hline Parameter & RSV & CLO \\
\hline Concentration range $(\mu \mathrm{g} / \mathrm{ml})$ & $6-16$ & $45-120$ \\
Slope $(\mathrm{m})$ & 47831 & 7103.4 \\
Tailing factor & 3050.8 & 6366 \\
Coefficient correlation $\left(\mathrm{r}^{2}\right)$ & 0.9999 & 0.9996 \\
\hline
\end{tabular}

RSV: Rosuvastatin, CLO: Clopidogrel bisulfate

Table 4: Recovery results

\begin{tabular}{lllll}
\hline Drug & $\begin{array}{l}\text { Level } \\
(\%)\end{array}$ & $\begin{array}{l}\text { Amount taken } \\
(\boldsymbol{\mu g} / \mathbf{m l})\end{array}$ & $\begin{array}{l}\text { Amount found* } \\
(\boldsymbol{\mu g} / \mathbf{m l})\end{array}$ & \% Recovery* \\
\hline RSV & 80 & 8 & 8.11 & 101.37 \\
& 100 & 10 & 10.01 & 100.12 \\
& 120 & 12 & 12.05 & 100.41 \\
CLO & 80 & 60 & 59.83 & 99.72 \\
& 100 & 75 & 75.81 & 101.09 \\
& 120 & 90 & 90.75 & 100.83 \\
\hline
\end{tabular}

*Average of three determinations. RSV: Rosuvastatin, CLO: Clopidogrel bisulfate

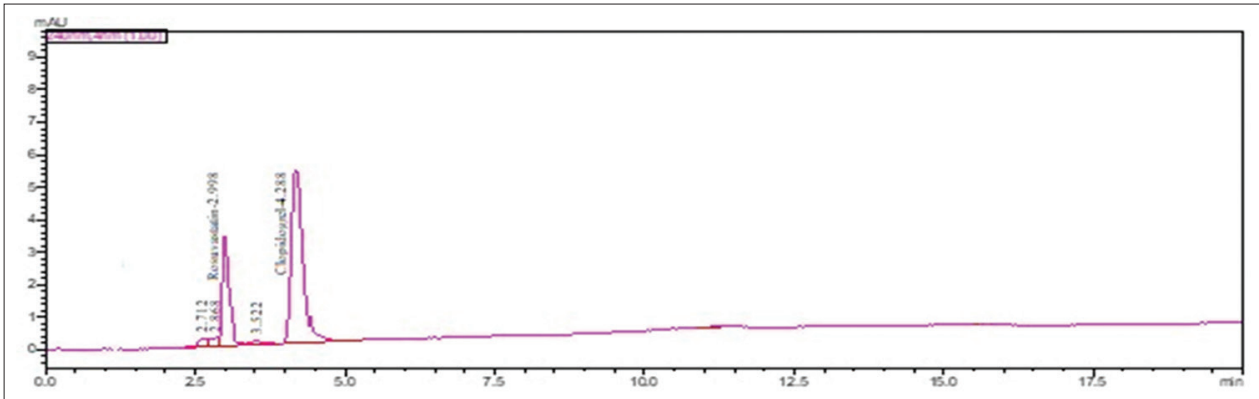

Fig. 7: Chromatogram of RSV and CLO degraded with acid hydrolysis. Rosuvastatin calcium (RSV) and clopidogrel bisulfate (CLO) with Rt of $2.998 \mathrm{~min}$ and $4.288 \mathrm{~min}$, respectively, and degradation products of RSV with Rt2.712 and $2.868 \mathrm{~min}$ and degradation products of CLO with Rt3.522 min

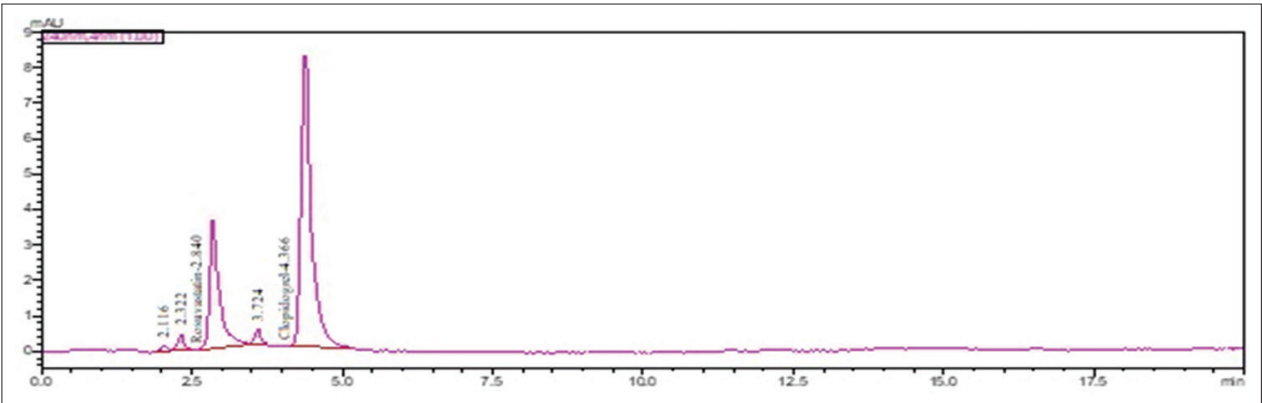

Fig. 8: Chromatogram of RSV and CLO degraded with alkali hydrolysis. Rosuvastatin calcium (RSV) and clopidogrel bisulfate (CLO) with Rt of 2.840 min and 4.366 min, respectively, and degradation products of RSV with Rt 2.322 min and degradation products of CLO with Rt 2.116 and $3.724 \mathrm{~min}$ 
Table 5: Summary of validation parameter

\begin{tabular}{lll}
\hline Parameter & RSV & CLO \\
\hline Calibration range $(\mu \mathrm{g} / \mathrm{ml})$ & $6-16$ & $45-120$ \\
Optimized wavelength $(\mathrm{nm})$ & 240 & 240 \\
Retention time & 2.844 & 4.388 \\
Regression equation $(\mathrm{Y})$ & $\mathrm{Y}=47831 \mathrm{x}+3050.8$ & $\mathrm{Y}=7103.4 \mathrm{x}+6366$ \\
Slope & 47831 & 7103.4 \\
Intercept & 3050.8 & 6366 \\
Coefficient correlation $\left(\mathrm{r}^{2}\right)$ & 0.9999 & 0.9996 \\
Precision $(\% \mathrm{RSD})$ & & \\
$\quad$ Intraday & 0.6 & 0.8 \\
Interday & 0.9 & 0.4 \\
$\quad \%$ Assay* & 98.99 & 99.92 \\
LOD $(\mu \mathrm{g} / \mathrm{ml})$ & 0.65 & 6.90 \\
LOQ $(\mu \mathrm{g} / \mathrm{ml})$ & 1.98 & 20.91 \\
\hline
\end{tabular}

*Average of five determinations, LOD: Limit of detection, LOQ: Limit of quantification. RSV: Rosuvastatin, CLO: Clopidogrel bisulfate, RSD: Relative standard deviation of the result, it can be deduced that the variation in the changing wavelength, flow rate does not affect the method significantly. \%RSD $<2 \%$ specifies that the developed method was robust. The results of robustness are shown in Table 6 .

Analysis of RSV calcium and CLO from marketed tablets

The percentage assays of tablet formulation were found to be 98.99 and $99.92 \%$ for RSV and CLO, respectively. The stability of the drug solution was observed for $24 \mathrm{~h}$. In degradation studies, the drug was exposed to various stress conditions. From the chromatograms of stressed samples, it was found that no interference from degradants was observed at the retention time of RSV calcium and CLO. Optimum degradation was observed in the presence of acid and alkali. Substantial degradation was observed in the presence of water, light, and peroxide. No degradation was observed in the presence of heat for RSV and CLO. The results of the percentage of degradation are presented in Table 7 and Figs. 7-12. Hence, the method was found to be specific.

Table 6: Robustness results

\begin{tabular}{|c|c|c|c|c|}
\hline \multirow[t]{2}{*}{ Condition } & \multicolumn{2}{|l|}{ RSV } & \multicolumn{2}{|l|}{ CLO } \\
\hline & Amount estimated* (\%) & RSD (\%) & Amount estimated*(\%) & RSD (\%) \\
\hline Change in wavelength $238 \mathrm{~nm}$ & 97.28 & 0.5698 & 100.16 & 0.0900 \\
\hline$(240 \pm 2 \mathrm{~nm}) 242 \mathrm{~nm}$ & 98.21 & 0.5733 & 100.08 & 0.1417 \\
\hline Change in flow rate $0.9 \mathrm{ml} / \mathrm{min}$ & 99.55 & 0.6381 & 99.37 & 0.2068 \\
\hline$(1.0 \pm 0.1 \mathrm{ml} / \mathrm{min}) 1.1 \mathrm{ml} / \mathrm{min}$ & 99.24 & 0.5078 & 99.56 & 0.2009 \\
\hline
\end{tabular}

*Average of three determinations, \%RSD: Percentage relative standard deviation. RSV: Rosuvastatin, CLO: Clopidogrel bisulfate, RSD: Relative standard deviation

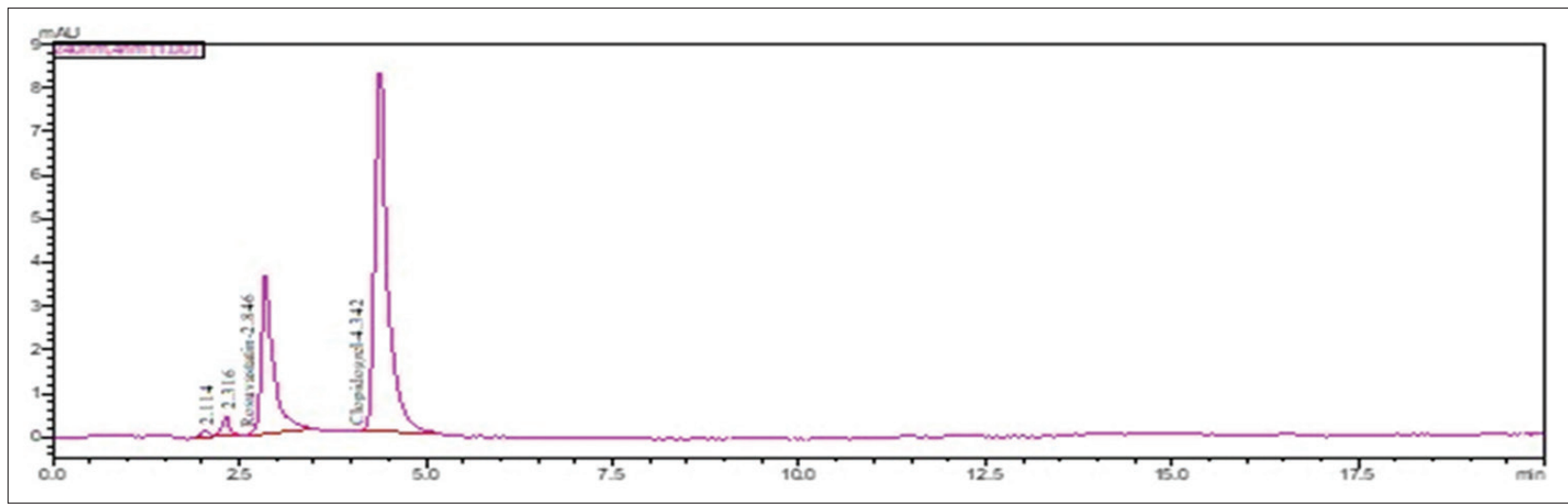

Fig. 9: Chromatogram of RSV and CLO degraded with neutral hydrolysis. Rosuvastatin calcium (RSV) and clopidogrel bisulfate (CLO) with Rt of $2.846 \mathrm{~min}$ and $4.342 \mathrm{~min}$, respectively, and degradation products of RSV with Rt 2.114 and 2.316 min and no degradation products of CLO

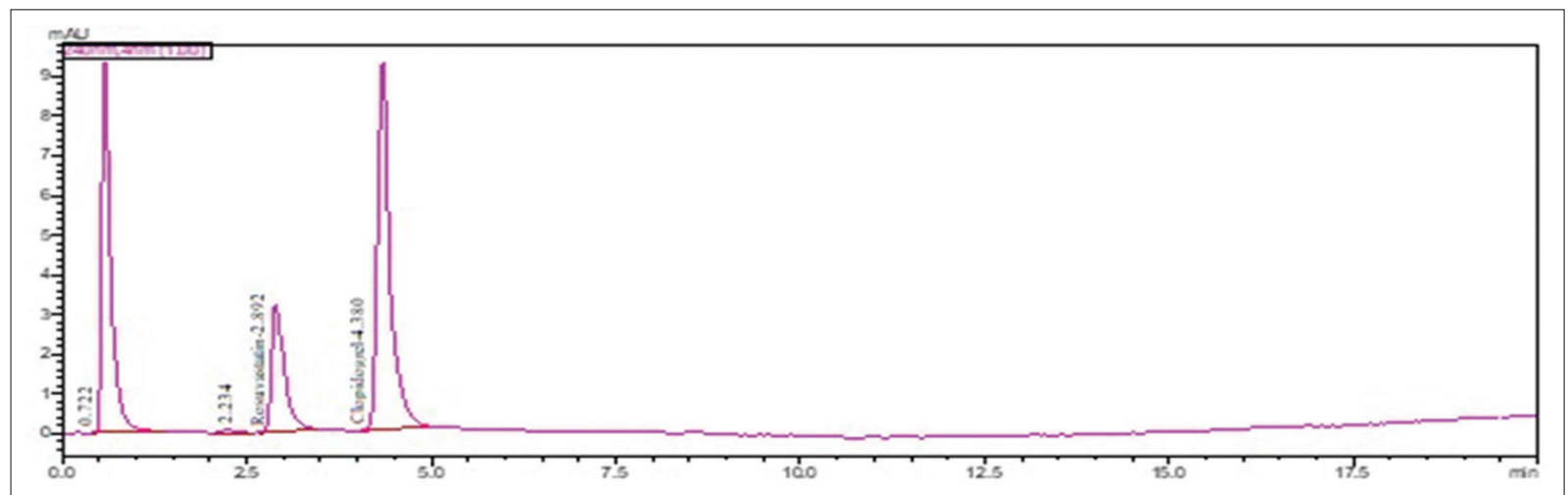

Fig. 10: Chromatogram of RSV and CLO degraded with oxidative hydrolysis. Rosuvastatin calcium (RSV) and clopidogrel bisulfate (CLO) with Rt of $2.892 \mathrm{~min}$ and $4.380 \mathrm{~min}$, respectively, and degradation products of RSV with Rt0.722 and 2.234 min and no degradation products of CLO 


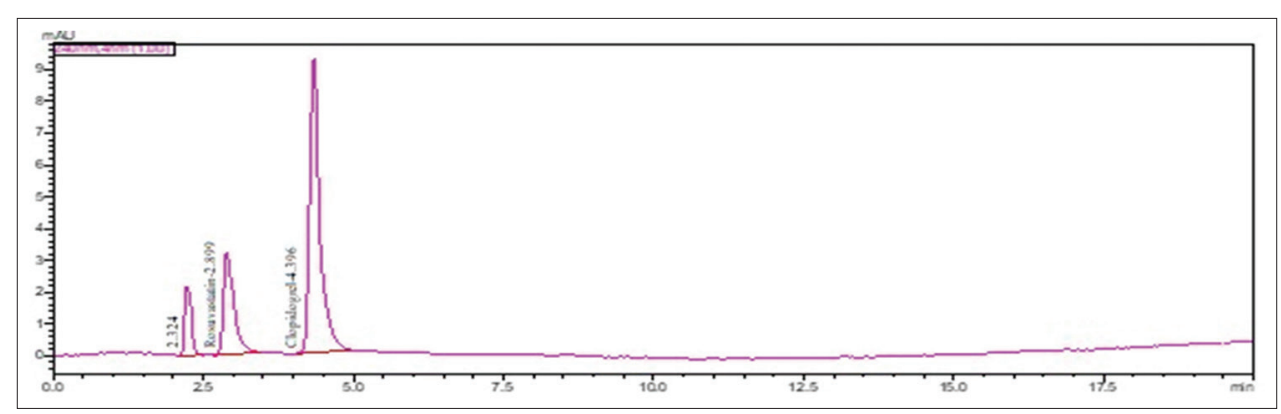

Fig. 11: Chromatogram of RSV and CLO degraded with exposed to direct sunlight. Rosuvastatin calcium (RSV) and clopidogrel bisulfate (CLO) with Rt of $2.899 \mathrm{~min}$ and $4.396 \mathrm{~min}$, respectively, and degradation products of RSV with Rt 2.324 min and no degradation products of CLO

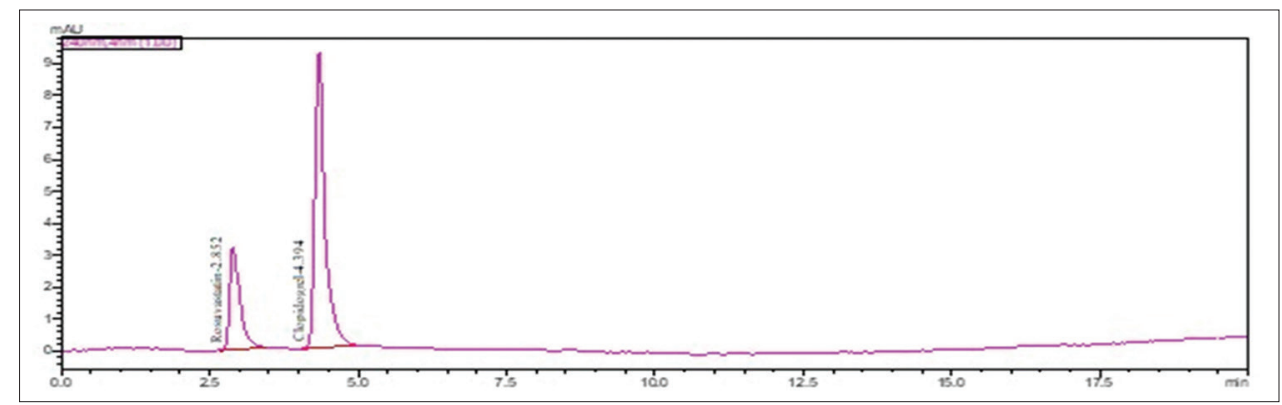

Fig. 12: Chromatogram of RSV and CLO degraded with thermal hydrolysis. Rosuvastatin calcium (RSV) and clopidogrel bisulfate (CLO) with Rt of $2.852 \mathrm{~min}$ and $4.394 \mathrm{~min}$, respectively, and no degradation products of RSV and CLO

Table 7: Stability-indicating method data for RSV and CLO

\begin{tabular}{|c|c|c|}
\hline Stress condition & $\begin{array}{l}\text { RSV } \\
\text { (\%Degradation) }\end{array}$ & $\begin{array}{l}\text { CLO } \\
\text { (\%Degradation) }\end{array}$ \\
\hline Acidic $(0.1 \mathrm{~N} \mathrm{HCl}$ for $24 \mathrm{~h})$ & 9.29 & 8.26 \\
\hline $\begin{array}{l}\text { Alkaline }(0.1 \mathrm{~N} \mathrm{NaOH} \text { for } \\
24 \mathrm{~h})\end{array}$ & 8.72 & 6.24 \\
\hline $\begin{array}{l}\text { Hydrolytic (HPLC waters } \\
\text { for } 24 \mathrm{~h} \text { ) }\end{array}$ & 6.16 & No degradation \\
\hline $\begin{array}{l}\text { Oxidative }\left(0.3 \% \mathrm{H}_{2} \mathrm{O}_{2} \text { for }\right. \\
24 \mathrm{~h})\end{array}$ & 7.82 & No degradation \\
\hline $\begin{array}{l}\text { Photo (Sunlight for } 30 \\
\text { days) }\end{array}$ & 1.45 & No degradation \\
\hline $\begin{array}{l}\text { Thermal (Sand bath at } \\
50^{\circ} \mathrm{C} \text { for } 24 \mathrm{~h} \text { ) }\end{array}$ & No degradation & No degradation \\
\hline
\end{tabular}

HPLC: High-performance liquid chromatography, RSV: Rosuvastatin, CLO: Clopidogrel bisulfate

\section{CONCLUSION}

The method enables simple, rapid, accurate, precise, specific, economical, and sensitive analysis of RSV calcium and CLO in bulk and tablet dosage form. This method was validated as per ICH guidelines. The method can, therefore, be used for routine quality control analysis RSV calcium and CLO in bulk and tablet dosage form.

\section{ACKNOWLEDGMENTS}

The authors extend their sincere thanks to Cadila Pharmaceuticals Ltd., Ahmadabad (India), for providing gift sample of pure RSV calcium and CLO. We also extend our thanks to the Head of Department, Department of Pharmaceutical Sciences, RTM Nagpur University, Nagpur, for providing the necessary facilities.

\section{AUTHORS' CONTRIBUTIONS}

$\mathrm{AP}$ and RK designed the study. AP performed the experiment, and analyzed the data, and reviewed it. RK supervised the experiment, reviewed the data, and supported for writing the manuscript.

\section{CONFLICTS OF INTEREST STATEMENT}

Authors declare that they have no conflicts of interest that exist in this investigation.

\section{REFERENCES}

1. The United States Pharmacopeia. National Formulary 24, US Pharmacopeal Convention; 2007. p. 796.

2. Available from: https://www.en.wikipedia.org/wiki/rosuvastatin.

3. The United States Pharmacopeia. National Formulary 24, US Pharmacopeal Convention; 2007. p. 1280.

4. Available from: https://www.en.wikipedia.org/wiki/clopidogrel.

5. Sailaja B, Kumari KS. Stability-indicating method development and validation for the estimation of rosuvastatin calcium in bulk and tablet formulation by reverse-phase high-performance liquid chromatography. Asian J Pharm Clin Res 2019;12:251-6.

6. Pathan M, Kshirsagar A. Development of validated stability indicating method by RP-HPLC for simultaneous estimation of meropenem and vaborbactam in bulk and pharmaceutical formulation. Int J Pharm Pharm Sci 2019;11:102-8.

7. Rajesh R, James JJ. A validated RP-HPLC method for simultaneous estimation of pyrantel pamoate and praziquantel in bulk and pharmaceutical dosage form. Int J Pharm Pharm Sci 2019;11:62-7.

8. Al-Bathish MY, Gazy AA, El-Jamal MK. RP-HPLC and chemometric methods for the determination of two anti-diabetic mixtures; metformin hydrochloride-canagliflozin and metformin hydrochloride-gliclazide in their pharmaceutical formulation. Int J Pharm Pharm Sci 2020;12:83-94.

9. Damle MC, Waghmare SS, Sinha P. Development and validation of stability indicating HPTLC method for determination of apixaban as bulk drug. Int J Pharm Pharm Sci 2019;11:37-42.

10. Aher SS, Saudagar RB, Kothari H. Development and validation of RPHPLC method for simultaneous estimation of azilsartan medoxomil and chlorthalidone in bulk and tablet dosage form. Int J Curr Pharm Res 2018;10:21-4.

11. Choppella V, Badipati S, Gonthina H, Chukka VK. Stability indicating method development and validation for simultaneous quantification of sorafenib and regorafenib drug substances by using RP-UPLC. Int J Curr Pharm Res 2020;12:56-62.

12. Chengalva P, Kuchana M. Stability indicating UPLC method for simultaneous determination of phenylephrine hydrochloride, chlorpheniramine maleate, paracetamol, guaiphenesin and bromhexine hydrochloride in bulk and pharmaceutical formulation. Int J Appl 
Pharm 2019;11:284-92.

13. Kuchana M, Kandukuru C, Chengalva P. Development and validation of RP-HPLC method for simultaneous estimation of ciprofloxacin and fluocinolone acetonide in bulk and pharmaceutical dosage form. Int $\mathrm{J}$ Appl Pharm 2020;12:134-8.

14. Rajput P, Shah DB, Maheshwari DG. A review on chromatographic method for estimation of rosuvastatin calcium. Int J Res Pharm Pharm Sci 2018;3:28-31.

15. Thammera RK, Shitut NR, Pasikanti KK, Menon VC, Venkata VP, Mullangi R. Determination of rosuvastatin in rat plasma by HPLC and its application to pharmacokinetic studies. Biomed Chromatogr 2006;20:881-7.

16. Hassouna ME, Salem HO. Stability indicating new RP-HPLC method for the determination of rosuvastatin calcium in pure and tablets dosage forms. Int J Appl Pharm Biol Res 2017;2:11-27.

17. Mulukuri NV, Srinivasarao T, Raveendra BG. New RP-HPLC method development and validation for the estimation of rosuvastatin calcium in bulk drugs and formulations. J Pharm Res 2017;11:257-60.

18. Hasumati AR, Rajput SJ, Dave JB, Patel CN. Development and validation of two chromatographic stability-indicating methods for determination of rosuvastatin in pure from and pharmaceutical preparation. Int J ChemTech Res 2009;1:677-89.

19. Trivedi HK, Patel MC. Development and validation of a stabilityindicating RP-UPLC method for determination of rosuvastatin and related substances in pharmaceutical dosage form. Sci Pharm 2012;80:393-406.

20. Singh SS, Sharma K, Patel H, Jain M, Shah H, Gupta S. Estimation of rosuvastatin in human plasma by HPLC tandem mass spectroscopic method and its application to bioequivalence study. J Braz Chem Soc
2005; $16: 944-50$.

21. Bahrami G, Mohammadi B, Mirzaeei S, Kiani A. Determination of atorvastatin in human serum by reversed-phase high performance liquid chromatography with UV detection. J Chromatogr B 2005;826:41-5.

22. Panchal HJ, Suhagia BN, Patel NJ, Rathod IS, Patel BH. Simultaneous estimation of atorvastatin calcium, ramipril and aspirin in capsule dosage form by RPLC. Chromatographia 2009;69:91-5.

23. Kadav A, Vora DN, Stability indicating UPLC method for simultaneous determination of atorvastatin calcium, fenofibrate and their degradation products in Tablets. J Pharm Biomed Anal 2008;48:120-6.

24. Madala A, Keerthisikha P. A new stability indicating method development and validation of RP-HPLC method for the simultaneous estimation of rosuvastatin calcium and fenofibrate in tablet dosage form. Indo Am J Pharm Sci 2016;3:953-9.

25. Rajput SJ, George RK, Ruikar DB. Chemometric simultaneous estimation of clopidogrel bisulfate and aspirin from combined dosage form. Indian J Pharm Sci 2008;70:450-4.

26. Chaudhari PB, Pawar PD, Narkhede KP. Stability indicating spectrophotometric method for determination and validation of clopidogrel bisulfate in tablet dosage form. Int J Res Ayureda Pharm 2010;1:418-23.

27. Himani A, Neeraj K, Paradkar AR, Mahadik KR. Stability indicating HPTLC determination of method for clopidogrel bisulfate as bulk drug and in pharmaceutical dosage form. J Pharm Biomed Anal 2003;61:581-9.

28. International Conference on Harmonisation. Stability Testing of New Drug Substances and Products. Geneva: Proceedings of the International Conference on Harmonisation; 1993.

29. Available from: https://www.ich.org/fileadmin/public_web_site/ich products/guidelines/quality/q2_r1/step4/q2_r1_guideline.pdf. 